Research article

\title{
Effects of the oral administration of silver nanoparticles on wound healing in male rats
}

\section{Samiee-Rad F, Sofiabadi M, Habibian Z and Gheibi N}

\section{Keywords Wound, silver nanoparticles, healing}

For referencing Samiee-Rad F et al. Effects of the oral administration of silver nanoparticles on wound healing in male rats. Wound Practice and Research 2020; 28(1):8-16.

DOI https://doi.org/10.33235/wpr.28.1.8-16

\section{Abstract}

Background For years, silver has been used for the treatment of skin injuries.

Objective The effect of the oral administration of silver nanoparticles on the wound healing process in male rats was studied.

Materials and methods In this experimental study, 30 Wistar male rats were randomly allocated to three groups - the control and two silver nanoparticles treatment groups (30ppm and 60ppm AgNPs concentration). In all rats, the full- thickness wound was induced under general anesthesia. At 12 days post-wounding, microscopic evaluation of wound healing - for example inflammatory cells, fibroblasts, angiogenesis and collagen density - was completed.

Results The percentage of wound healing between the control and the treatment groups on the 12th day was significant $(p<0.001)$. Moreover, the number of inflammatory

Fatemeh Samiee-Rad MD

Metabolic Research Center

Qazvin University of Medical Sciences, Iran

Mohammad Sofiabadi PhD

Cellular and Molecular Research Center

University of Medical Sciences, Qazvin, Iran

Zoheir Habibian

General Physician, Faulty of Medicine

University of Medical Sciences, Qazvin, Iran

Nematollahe Gheibi* PhD

Professor, Department of Biochemistry \& Genetics

Cellular and Molecular Research Center

University of Medical Sciences, Qazvin, Iran

Email gheibi_n@yahoo.com

* Corresponding author cells was significantly higher in the control than in the treatment groups $(p<0.001)$. The difference between the fibroblast number and collagen density was more in the treatment groups than in the control $(p<0.001)$. Also, a considerable difference was observed between the number of inflammatory cells and fibroblasts in the $60 \mathrm{ppm}$ compared to the 30ppm concentration.

Conclusion By inducing anti-inflammatory effects and increasing the proliferation of fibroblasts and the expression of collagen, silver nanoparticles at a concentration of $30 \mathrm{ppm}$ accelerated the wound healing process.

\section{Introduction}

Wound healing is a dynamic response to injury. It involves a complex and well-ordered process and requires interaction among diverse cells, scleroproteins, proteinase and growth factors. In addition, mast cells and macrophages play a crucial role in repairing wounds ${ }^{1}$. Wound healing is divided into three stages which overlap in time - haemostasis and inflammation; proliferation; and remodelling and maturation. Irrespective of the cause of their infliction, all wounds go through these three phases².

In the first stage, a fibrin clot is formed, acting as a scaffold for the migration of inflammatory cells to the wound site. Polymorphonuclears (PMNs) are the first and macrophages come later; these infiltrate cells which enter the wound site. These are the major source of cytokines, particularly TNF- $\alpha$ which induces inflammation. They contribute to the degradation of the wound matrix and induce the migration of neutrophils; the factors released from these neutrophils cause a delay in healing the wound ${ }^{3}$. Macrophages participate in wound debridement and have a key role in the regulation of angiogenesis, matrix deposition and remodelling ${ }^{3}$.

In the proliferative phase, fibroblasts appear on the scene to form collagen and endothelial cells for angiogenesis. The 
formation of collagen depends on systematic factors such as sufficient oxygenation, provision of nutrients, cofactors and local wound environment ${ }^{3}$. Finally, maturation and remodelling begin during the fibroplasia phase. The strength of a wound is assessed by the quality and quantity of deposited collagen. Epithelialisation initiates one day after injury and continues over several days depending on the size of the wound ${ }^{3}$.

The human body is always subject to accidents which might inflict wounds; therefore, treating wounds is of significance in the world of medicine. Silver has long been valued as a rare and precious element and has been extensively used for thousands of years. Nanoparticles, due to their small size, have unique physical, chemical, mechanical, electronic and magnetic properties. Therefore, they can freely enter the cell and interfere in its natural process ${ }^{4}$.

Due to their antimicrobial effects and widespread commercial application, silver nanoparticles are used in a large number of applications such as in the health and beauty industries ${ }^{5}$. These bactericidal effects of silver have been known to mankind for centuries. In wars, soldiers used silver coins wrapped against wounds to prevent infection and accelerate healing. The ionic (colloidal) form of silver has antibacterial, antifungal and antiviral properties ${ }^{6}$ and, as such, a number of microbes have been known to be sensitive to nanosilver ${ }^{7}$. In medicine, wound dressings, surgical instruments and bone prostheses are coated with nanosilver ${ }^{8}$.

However, studies on silver nanoparticles are few; most of these are on the effects of inhaling silver nanoparticles ${ }^{9}$, the effects of their dermal absorption ${ }^{10}$ or their cytotoxic effects ${ }^{11}$, however, their oral application has not yet been widely studied ${ }^{12}$. Several studies have shown that silver nanoparticles could inhibit the development of viruses and microorganisms and, moreover, be active in controlling the antibacterial system in many ways ${ }^{13,14}$. Silver nanoparticles have a more chemically reactive nature and therefore a strong electrical effect compared to silver due to the larger surface area. Also, the quantum behaviour of silver nanoparticles can dominate other physical and chemical properties ${ }^{15,16}$. Previous research has shown a significant association between the biodistribution of silver nanoparticles with consumption routes, animal gender, size, shape, concentration, chemical composition, surface coating, aggregation, stability, and the purities of them. Therefore, organ distribution and removal of silver nanoparticles would mainly result from these properties but are not of one nature, including silver nanoparticles ${ }^{17,18}$.

van der Zande et al. ${ }^{19}$ reported that the silver concentration and biodistribution in various organs was tightly associated with the silver ion concentration in the silver nanoparticles mixture, because silver ions exclusively uptake across the gastrointestinal system and are stored in the liver and spleen macrophages. In addition, silver nanoparticles' biodistribution has a strong relation with available silver ions but not with silver nanoparticle size ${ }^{19}$.
One of the important plausible mechanisms of wound healing induced by silver nanoparticles, apart from anti-inflammatory properties, is their antibacterial effects ${ }^{20}$. Silver nanoparticles can cause an impressive decline in bacterial colonisation of the wound area $^{21}$. As mentioned above, microorganisms, for example bacteria or fungi, are found in chronic wounds and, if present in a wound, can rapidly proliferate and seriously impede wound healing. Thus, levels of bacteria and multi-resistant organisms can influence the wound healing process $^{22}$. As such, the use of silver-containing compounds as antimicrobial agents is one of the most important routine treatments for wounds. Therefore, the aim of this study was to evaluate the effect of oral nanosilver on the quality and quality of wound healing in male rats.

\section{Methods And Materials}

Sample

In this experimental study, 30 Wistar male rats (230-250g), were obtained from Razi Institute (Karaj, Iran). They were individually caged and kept under identical dietary and standard environmental conditions $\left(25 \pm 1^{\circ} \mathrm{C}\right.$ temperature and humidity 55\% with 12-hour light/dark cycles) in Qazvin University's animal house. They were handled according to the Declaration of Helsinki 1975 and the ethical code of IR.QUMS.REC.1394.183 from the Ethics Committee of Qazvin University of Medical Sciences (QUMS).

Anaesthesia and surgery

First, the each rat was anaesthetised with ketamine-xylazine (50 mg/kg ketamine, $5 \mathrm{mg} / \mathrm{kg}$ xylazine; Merck, Germany), then the sites were shaved and cleaned with Betadine (Tolid Darou, Iran). Next, in a sterile condition, a circular fullthickness incision, $2 \mathrm{~cm}$ in diameter, was made on the nape of each animal's neck with scissors.

After surgery the rats were kept individually in a clean cage and the wound site was washed with normal saline each day. A total of 30 Wistar male rats were randomly allocated to three groups of 10 - the control and two silver nanoparticles treatment groups that received 30ppm and $60 \mathrm{ppm}$ concentration of nanoparticles once a day as gavage.

\section{Nanoparticle preparation}

Spherical silver nanoparticles were purchased from Nano Danesh Caspian Co (Tehran, Iran) and were chemically prepared through citrate reduction. Fresh aqueous solutions of $\mathrm{NaBH} 4(2 \mu \mathrm{M})$ and Trisodium citrate $(2 \mu \mathrm{M})$ were vigorously stirred and heated to $60^{\circ} \mathrm{C}$ for 30 minutes in the dark. Then the $\mathrm{AgNO}_{3}$ solution $(1.17 \mu \mathrm{M})$ was added drop-wise to the mixture and the temperature was raised to $90^{\circ} \mathrm{C}$. The $\mathrm{pH}$ of the mix solution was adjusted to 10.5 using $\mathrm{NaOH}$ and the solution was heated for 20 minutes. Unreacted silver nanoparticles solution was removed by centrifugation (12000rpm, 15 minutes). After the re-dispersion, the pellet with Deionised (DI) water, the solution was pelleted (14000rpm for 20 
Table 1. Histological changes in wound healing.

\begin{tabular}{|c|c|c|c|c|c|}
\hline Score / Indicator & 0 & 1 & 2 & 3 & 4 \\
\hline Angiogenesis & $\begin{array}{l}\text { Absence of } \\
\text { angiogenesis }\end{array}$ & $\begin{array}{l}4-5 \text { vessels per } \\
\text { site }\end{array}$ & $\begin{array}{l}12-15 \text { vessels per } \\
\text { site }\end{array}$ & $\begin{array}{l}\text { 15-20 vessels per } \\
\text { site }\end{array}$ & $\begin{array}{l}\text { More than } 20 \\
\text { vessels per site }\end{array}$ \\
\hline $\begin{array}{l}\text { Granulation } \\
\text { tissue formation }\end{array}$ & $\begin{array}{l}\text { Inflammatory } \\
\text { exudate in } \geq 70 \% \\
\text { of the tissue }\end{array}$ & $\begin{array}{l}\text { Inflammatory } \\
\text { exudate and } \\
\text { granulation tissue } \\
\text { in } \geq 60 \% \text { of the } \\
\text { tissue }\end{array}$ & $\begin{array}{l}\text { Granulation tissue } \\
\text { in } \geq 40 \% \text { of the } \\
\text { tissue }\end{array}$ & $\begin{array}{l}\text { Presence of } \\
\text { large granulation } \\
\text { tissue, together } \\
\text { with the formation } \\
\text { of collagen } \\
\text { fibrils and } \\
\text { vessels vertically } \\
\text { disposed toward } \\
\text { collagen fibrils }\end{array}$ & $\begin{array}{l}\text { Complete tissue } \\
\text { formation in } \geq 80 \% \\
\text { of the tissue }\end{array}$ \\
\hline
\end{tabular}

minutes) and the pellet solved in DW. The size distribution of silver nanoparticles was obtained approximately $10 \mathrm{~nm}$ and the concentration was $500 \mathrm{ppm}^{23}$. The serial dilution method was utilised to prepare the dilutions from the original stock solution.

\section{Histological study}

Histological studies were carried out on the 12th day which represented the phase of active wound healing. The rats were anaesthetised by ketamine-xylazine $(50 \mathrm{mg} / \mathrm{kg}$ ketamine, $5 \mathrm{mg} / \mathrm{kg}$ xylazine) and a sample was obtained from the wound tissue nearby healthy skin ( $5 \mu \mathrm{m}$ thick) and fixed in $10 \%$ formalin without washing. After these stages, blocking was done with paraffin. The sections were prepared in a serial form using a Leitz microtome. The haematoxylin and eosin staining technique was used for staining and examining angiogenesis, inflammatory cells - neutrophils, eosinophils and mast cells - and fibroblasts. Neutrophils, eosinophils, mast cells and fibroblasts were counted with a 400x objective lens. In order to count angiogenesis, first regions with the high density of new vessels were identified using $100 x$ objective lens, and then three fields in the regions were selected and counting was performed with $400 x$ magnification.

The cells' discrimination was based on morphological characteristics. Neutrophil was a round cell with a segmented nucleus (2-5 lobes), obvious pink cytoplasm, and abundant fine specific granules ${ }^{24}$. A mast cell was oval shaped with dense granular cytoplasm and centrally located nucleus ${ }^{25}$. Eosinophil was a round cell with large eosinophilic cytoplasmic granules and bi-lobed nucleus ${ }^{26}$. Angiogenesis was the formation of new blood vessels and was defined by tubular structures lined by endothelial cells and containing red blood cells ${ }^{27}$. Moreover, collagen was demonstrated by Van Gieson staining and the density of collagen fibres in stained tissues was scored by Talas' trichrome staining method $^{28}$. Histological changes in the scoring of wound healing is demonstrated in Table 1. Based on epithelialization, angiogenesis and granulation tissue formation and progression of them wound healing was scored.

\section{Percentage of wound healing}

The percentage of wound healing on the 2nd, 4th, 6th, 8th and 10th days after creating the wound was determined by measuring the area of the wound in $\mathrm{mm}^{2}$. In order to measure the surface of the wound, the animals was held in the standard crouching position, then the shape of the wound was drawn on transparent paper and, finally, its surface was determined with AutoCAD software ${ }^{29}$. Moreover, a formula was applied to determine the percentage of healing (see below).

$$
\text { Would healing percentage }=\frac{\text { Initial wound surface }- \text { Nth day wound surface }}{\text { Initial wound surface }} \times 100
$$




\section{Statistical analysis}

In the present study, all results were expressed as Mean \pm SEM error of the mean. Data analysis was carried out with the SPSS software v.20. The ANOVA statistical method, and post-hock Tukey's Test, were applied; $p<0.05$ were assigned significant level.

\section{Results}

The study tested whether silver nanoparticles might alter the number of immune cells entering a wound. The number of inflammatory cells was counted and recorded. The number of PMNs was $34.8 \pm 2.9$ in the control group compared to $24 \pm 1.9$ and $19 \pm 2.5$ after treatment with AgNPs 30ppm and AgNPs 60ppm, respectively. The number of eosinophils was $4 \pm 1$ in the control group compared to $1.7 \pm 0.4$ and $0.25 \pm 0.1$ after treatment with AgNPs 30ppm and 60ppm, respectively. The number of mast cells was $4.7 \pm 0.94$ in the control group compared to $1.86 \pm 0.69$ and $1.88 \pm 0.64$ after treatment with AgNPs 30ppm and AgNPs 60ppm, respectively. The number of inflammatory cells was significantly higher in the control than in the treatment groups $(p<0.001)$ (Tables 2 and 3$)$. The comparison of the inflammatory cells - PMNs, eosinophils and mast cells - on the 12th day revealed an acceleration in the wound healing process (Table 2).

The study also tested whether silver nanoparticles might alter the number of fibroblasts and the density of collagen deposition. The number of fibroblasts and the density of collagen deposition were measured and recorded. The number of fibroblast was $73.2 \pm 2.8$ in the control group compared to $103.5 \pm 4.7$ and $79.6 \pm 2.8$ after treatment with AgNPs 30ppm and AgNPs 60ppm, respectively. The collagen density was $1.2 \pm 0.42$ in the control group compared to 3 and $2.63 \pm 0.51$ after treatment with AgNPs 30ppm and AgNPs $60 \mathrm{ppm}$, respectively. The difference between the fibroblast number and collagen density was bigger in the treatment groups than in the control $(\mathrm{p}<0.001)$ (Tables 2 and 3$)$.

The collagen density showed a significant difference from the control group and also depended on the dose of nanoparticles (Table 2). Moreover, the collagen density in the 30ppm group was the highest. Also, a considerable difference was observed between the number of inflammatory cells and that of fibroblasts in the third group, in contrast to the number in the second group - decreased inflammatory

Table 2. The comparison of the means \pm SEM of the indicators in the three groups.

\begin{tabular}{|l|l|l|l|}
\hline Group / Indicator & Control & NSP 30ppm & NSP 60ppm \\
\hline PMN & $34.8 \pm 2.9$ & $24 \pm 1.9^{\star}$ & $19 \pm 2.5^{\star}$ \\
\hline Eosinophil & $4 \pm 1$ & $1.7 \pm 0.4^{\star}$ & $0.25 \pm 0.1^{\star}$ \\
\hline Mast cell & $4.7 \pm 0.94$ & $1.86 \pm 0.69^{\star}$ & $1.88 \pm 0.64^{\star}$ \\
\hline Collagen density & $1.2 \pm 0.42$ & $3^{\star}$ & $2.63 \pm 0.51^{\star}$ \\
\hline Epithelialisation & 2 & 3 & 2 \\
\hline Fibroblast & $73.2 \pm 2.8$ & $103.5 \pm 4.7^{\star}$ & $79.6 \pm 2.8^{\star}$ \\
\hline Granulation tissue & 2 & 3 & 3 \\
\hline
\end{tabular}

* Significant change in comparison with control group $p<0.05$.

Table 3. The comparison of the indicators in pairs in the three groups.

\begin{tabular}{|l|l|l|l|}
\hline Group / Indicator & Control vs NSP 30ppm & Control vs NSP 60ppm & NSP 30ppm vs NSP 60ppm \\
\hline PMN & $10.8^{\star}$ & $15.8^{\star}$ & $5 \bullet \bullet$ \\
\hline Eosinophil & $2.3^{\star}$ & $3.75^{\star}$ & $1.45 \bullet \bullet$ \\
\hline Mast cell & $2.84^{\star}$ & $2.82^{\star}$ & 0.02 \\
\hline Collagen density & $1.8^{\star}$ & $1.42^{\star}$ & 0.37 \\
\hline Epithelialisation & - & - & - \\
\hline Fibroblast & $30.3^{\star}$ & $6.4^{\star \star}$ & $23.9 \bullet$ \\
\hline Granulation tissue & - & - & - \\
\hline
\end{tabular}

* Significant change in comparison with control group $p<0.05$

** Significant change in comparison with control group $p<0.01$

- Significant change in comparison with silver nanoparticles 30 and 60ppm group $p<0.05$ - Significant change in comparison with silver nanoparticles 30 and $60 p p m$ group $p<0.01$

*** Significant change in comparison with control group $p<0.001$

$\bullet \bullet$ Significant change in comparison with silver nanoparticles 30 and 60ppm group $p<0.001$ 
Figure 1. The wound diameter (percentage of healing) in the groups with nanoparticles at a concentration of 30ppm and 60ppm and the control group. ( $n=10$ rats/group).

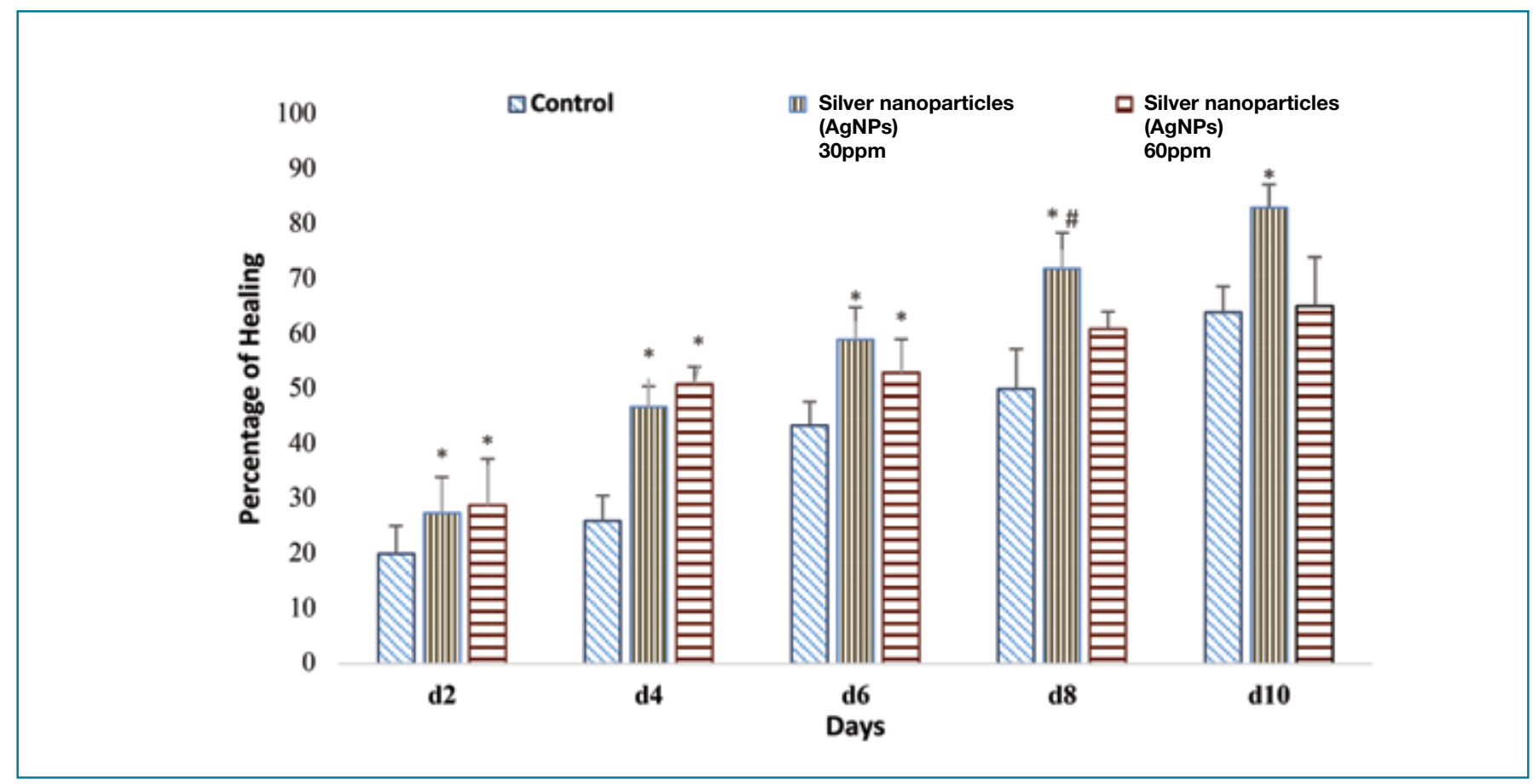

cells and fibroblasts - which indicated cytotoxic effects at a concentration of 60ppm and above.

Finally, the study tested whether silver nanoparticles might alter the creation and maturation of re-epithelialisation and also alter the transition of inflammatory to proliferation stage. The creation and maturation of re-epithelialisation and the granulation tissue formation were measured and recorded. The epithelialisation was 2 in the control group compared to 3 and 2 after treatment with AgNPs 30ppm and AgNPs $60 \mathrm{ppm}$, respectively. The granulation tissue formation was 2 in the control group compared to 3 and 3 after treatment with AgNPs 30ppm and AgNPs 60ppm, respectively. There was no crucial difference between the rate of epithelialisation and that of granulation tissue formation (Tables 2 and 3).

The percentage of wound healing was faster in the groups treated with silver nanoparticles, especially at a concentration of 30ppm compared to the control group. Moreover, the wound diameter on the second and fourth days was considerably reduced in the group with 60ppm; however, this effect was attenuated after 6, 8, 10 days. As the tenth day, the active phase of healing, was drawing closer, the percentage of healing in the group with $30 \mathrm{ppm}$ was the largest. The percentage of wound healing between the control and the treatment groups on the 12th day was also significant $(p<0.001)$. These are depicted in Figure 2.

An histomorphologic criteria of wound healing in the treated group with 30ppm silver nanoparticles was completed. The histomorphologic findings of wound healing in different groups are shown in Figure 3. In the control, compared with treatment groups, the amount of fibrino-leukocytes exudate and inflamed granulation tissue in the wound area was significantly higher $(p<0.01)$ (Figure $3 A-F)$. Also, in the control (Figure 3G) and AgNPs 60ppm (Figure 3I), compared with AgNPs 30ppm (Figure $3 \mathrm{H}$ ) treatment group, epithelialisation, including bridging the keratinocytes across the wound, was more incomplete. In the AgNPs 60ppm group, compared with AgNPs 30ppm, the complete bridging of keratinocytes across the wound (Figure $3 \mathrm{I}, \mathrm{H}$ ), the proliferation of fibroblasts (Figure 3L,K) and the deposition of collagen fibres (Figure $30-R)$ in the repaired tissue of the wound were lower, respectively. In the AgNPs 30ppm group, compared with AgNPs 60ppm group, the epithelialisation (Figure $3 \mathrm{H}, \mathrm{I}$ ), the proliferation of fibroblasts (Figure $3 \mathrm{~K}, \mathrm{~L}$ ), and the deposition of collagen fibres (Figure $3 \mathrm{O}-\mathrm{R}$ ) in the repaired tissue of the wound were more complete. In the AgNPs 30ppm group, thick collagen fibre deposition was present (Figure $30, P)$, and in the AgNPs 60ppm group, thin collagen fibre deposition was present (Figure 3Q,R).

\section{Discussion}

Silver nanoparticles have many biological effects. In this study, the effect of silver nanoparticles are examined on the wound healing in male rats. Based the result, the percentage of wound healing was more significant in the treated groups with silver nanoparticles, especially at a concentration of $30 \mathrm{ppm}$ and at the primary phase wound healing. This effect was attenuated after 8 days in the group which received 60 ppm silver nanoparticles; this could be due to the cytotoxic effects of silver nanoparticles at a higher concentration. 

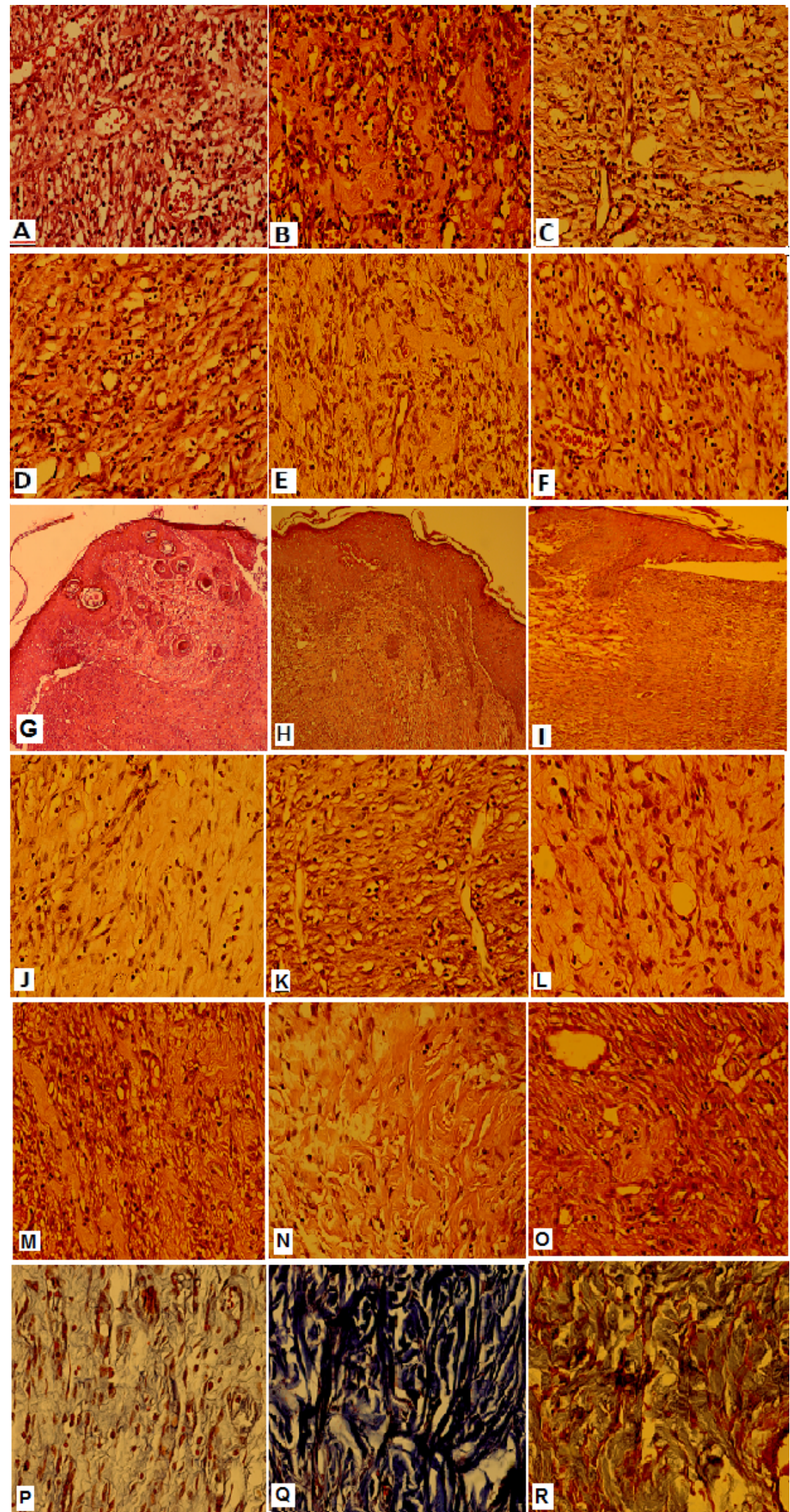

Figure2. Histopathologic findings of wound healing in the experiment groups:

$(A, B, C)$ The Inflammatory cells of control, SNP 30,60ppm groups respectively(H\&E; $x 400)$, (D,E,F) The Organized granulation tissue of control, SNP 30,60ppm groups (H\&E; x400), (G, H,I) The Epithelialization of control, SNP 30,60ppm groups (H\&E; x100) , (J,K,L) The Fibroblast proliferation in control, SNP 30,60ppm groups (H\&E; x400), (M,N,O) Thin collagen fibers deposition in control, SNP 30,60ppm groups (Trichrome staining; x400), (P,Q,R) Thick collagen fibers deposition in control, SNP 30,60ppm groups (Trichrome staining; x400). 
Moreover, at beginning of the treatment course, the number of inflammatory cells - including PMNs, eosinophils and mast cells - was significantly decreased in the treatment groups than in the control group. This result emphasises the antiinflammatory effect of silver nanoparticles which has a role on the acceleration of the wound healing process through these phases. The cytotoxic effect of silver nanoparticles cause cell injury or cell death of inflammatory cells, including PMNs, eosinophils, mast cells, macrophages and another residue cells, therefore the secretion of cytokines and growth factors from these cells leads to an accelerated role of silver nanoparticles in the wound healing process; this was observed on the 12th day ${ }^{30}$.

Other studies agree with these results. The findings of Andersson-Willman et al. ${ }^{31}$ show the immune cells cytotoxicity of another nanoparticle compound. In addition, there was no crucial difference between the rate of epithelialisation and that of granulation tissue formation, considering that the means of the groups were close to each other. However, considering the percentage of healing and the diameter of the wound, one could conclude that nanoparticles have a positive effect on the acceleration of wound healing.

The difference between the fibroblast number and collagen density was bigger in the treatment groups than in the control, especially at the middle period of nanoparticle treatment and in the 30ppm group. Furthermore, a reduction in the number of fibroblasts was observed in the group with 60ppm concentration, which may be the reason for its cytotoxic effects at higher concentrations.

The topical silver nanoparticles prescriptions have an approved role in the wound healing process ${ }^{32}$. The rate of reduction in wound size is a true measure of the wound healing rate assessment. There is a concurrent decrease in the wound surface and healing of the wound area; this is due to the contraction of the wound and deposition of connective tissue. Contraction is due to the presence of myofibroblasts. Owing to the contractile property, it stretches the epidermis and leads to the reduction in wound size. The rate of wound contraction, during which the size of the open wound decreases by moving toward the centre of the skin, might be possibly a result of the contractile properties of myofibroblasts in the granulation tissue of the wound $^{33}$

Tests concerning the measurement of the wound surface and the calculation of the healing percentage on the 12th day demonstrated that combinations of silver nanoparticles made a significant difference in the wound healing process compared with the control group and between the groups with $30 \mathrm{ppm}$ and with $60 \mathrm{ppm}$. During angiogenesis, a major factor in wound healing, the wound site becomes abundant in blood vessels, which is necessary for wound nutrition. Therefore, its absence inhibits healing. The factor which stimulates angiogenesis can cause the normal development of the healing process.
A major part of wound healing is owed to neovascularisation, without which the inrush of macrophages and fibroblasts into the wound, due to a lack of oxygen and nutrients, will never be effective. Fibroblasts are among the most important and effective cells which attempt to heal the wound. They arrive at the wound site and, during their proliferation, the rate of collagen synthesis keeps increasing for 3 weeks until a balance is achieved ${ }^{34}$.

In this study, the proliferation of fibroblasts and collagen density was more in the treated group and also depended on the dose of nanoparticles. Moreover, the collagen density in the 30ppm group was the highest. Considering the equality of the means, the comparison between granulation tissue and epithelialisation yielded no considerable difference. The results of this study clearly show the positive effect of silver nanoparticles on wound healing. Naghsh et al. ${ }^{35}$ investigated the effect of the composite of silver nanoparticles and Cucurbita pepo extract on wound healing in albino male mice placed in eight groups of eight. This study revealed that the nanosilver-Cucurbita pepo extract had synergic effects on burn wound healing ${ }^{35}$.

Studies on the effect of silver nanoparticles on the wound healing process are few; however, there are some studies on antibacterial effects. Numerous studies have been carried out on antimicrobial and cytotoxic effects of silver nanoparticles. For instance, Jiang et al. (2004) studied the silver nanoparticles-induced development of antimicrobial factors in blood. It showed the antimicrobial effect of silver nanoparticles ${ }^{15}$. Another study by Razavian et al. ${ }^{36}$ concluded that the oral consumption of these particles, particularly in high doses and in the long term, not only causes damage to the liver but also decreases the number of white blood cells and brings down the immunity level of the organism ${ }^{36}$. There are also other studies on effects of antimicrobial - particularly antibacterial, antiviral and antifungal - growth.

There are also studies, such as the study by Braydich-Stolle et al. (2005), which look at cytotoxic effects and the effect on germ cells and fibroblasts of silver nanoparticles. Toxicity in silver nanoparticles depends on their size, diameter and concentration ${ }^{11}$. Wijnhoven et al. ${ }^{37}$ showed that, with a change in the size and concentration of nanoparticles, their effects and distribution in the body vary. Ji et al. (2007) investigated effects of oral nanoparticles, $60 \mathrm{~nm}$ in diameter, on male rats. They showed that mononuclear white blood cells, due to an increase in apoptosis, reduced. The reason for this mechanism could be attributed to a change in the diameter of their nanosilver or difference in the method of treating with nanosilver ${ }^{38}$. For instance, Mohtashami et al. ${ }^{13}$, in a study on the synthesis of silver nanoparticles through chemical reduction and antibacterial effects, demonstrated that smaller silver nanoparticles through chemical reduction had better antibacterial effects on Gram-negative and Grampositive bacteria and inhibited the bacterial growth at $0.2 \mathrm{mM}$ concentration; however, larger nanoparticles had lesser effects $^{14}$. 
One possible mechanism for accelerating the healing of the wound which has resulted from skin burns in mice is enhancing the apoptosis of damaged cells at the burnt site and accelerating the healing process ${ }^{39}$. Nanosilver could also be used as a medicine in treating skin diseases, acne, various wounds and burns, bacterial and fungal diseases, digestive diseases, sexual diseases and AIDS. Nanosilver is a highly toxic substance which is accompanied by the production of reactive oxygen species. Lots of in-vitro studies have shown its dose-dependence ${ }^{15}$. During several biological events, such as contact with the cell membrane and absorption into the cell wall, silver ions change the membrane permeability of living cells and deactivate cellular enzymes by generating reactive oxygen species. These properties might have negative effects on the environment and health and lead to high toxicity of silver nanoparticles ${ }^{15,16}$.

\section{Conclusion}

Silver nanoparticles have been shown to have antibacterial, antiviral and antifungal properties. The results here suggest that silver nanoparticles may be useful in treating infected wounds. The injured cells from these effects accelerate wound healing by producing different mediators. Moreover, using these toxic effects for the remains of dead cells in skin wounds can be influential in wound healing and skin lesions. However, since the effect of these nanoparticles does not occur intelligently and therefore all cells are affected, one may possibly manage to minimise their detrimental effects and maximise their positive effects by changing their formulation. Therefore, the following is recommended for future studies to explore their effect on wound healing, particularly burns and mechanical trauma, with higher intelligence by developing new complexes from biocompatible silver nanoparticles.

\section{Acknowledgments}

We would like to thank the Research Deputy of Qazvin University.

\section{Conflict of Interest}

The authors declare no conflicts of interest.

\section{Funding}

We would like to thank the Research Deputy of Qazvin University of Medical Sciences for funding this study.

\section{References}

1. Young $A$, McNaught CE. The physiology of wound healing. Surgery 2011;29(10):475-479. doi: 10.1016/j.mpsur.2011.06.011

2. Gaje PN, Ceausu AR, Jitariu A, Stratul SI, Rusu LC, Popovici RA, et al. Mast cells: key players in the shadow in oral inflammation and in squamous cell carcinoma of the oral cavity [Internet]. BioMed Res Int 2016. doi: 10.1155/2016/9235080

3. de Oliveira Gonzalez AC, Fortuna Costa T, Araújo Andrade ZD, Alves Peixoto Medrado AR. Wound healing: a literature review.
An Bras Dermatol 2016 Sep-Oct;91(5):614-620. doi: 10.1590/ abd1806-4841.20164741

4. Ge L, Li Q, Wang M, Jun Ouyang J, Li X, MQ Xing M. Nanosilver particles in medical applications: synthesis, performance, and toxicity. Int J Nanomedicine 2014;9:2399-2407. doi: 10.2147/ IJN.S55015

5. Sukhanova A, Bozrova S, Sokolov P, Berestovoy M, Karaulov A, Nabiev I. Dependence of nanoparticle toxicity on their physical and chemical properties. Nanoscale Res Lett 2018;13:44. doi: 10.1186/s11671-018-2457-x

6. Arora S, Jain J, Rajwade JM, Paknikar KM. Interactions of silver nanoparticles with primary mouse fibroblasts and liver cells. YTAAP 2009;236(3):310-318.

7. J edrzejczyk RJ, Turnau K, Jodłowski PJ, Chlebda DK, Łojewski $\mathrm{T}$, Łojewska J. Antimicrobial properties of silver cations substituted to faujasite mineral. Nanomaterials (Basel) 2017 Aug 27;7(9). pii:E240. doi: 10.3390/nano7090240.

8. Şuhani MF, Baciut G, Baciut M, Şuhani R, Bran S. Current perspectives regarding the application and incorporation of silver nanoparticles into dental biomaterials. Clujul Med 2018 Jul;91(3):274-279. doi: 10.15386/cjmed-935

9. Hussain SM, Schlager JJ. Safety evaluation of silver nanoparticles: inhalation model for chronic exposure. Toxicol Sci 2009;108(2):223-224.

10. Cha K, Hong HW, Choi YG, Lee MJ, Park JH, Chae HK, et al. Comparison of acute responses of mice livers to shortterm exposure to nano-sized or micro-sized silver particles. Biotechnol Lett 2008;30(11):1893-1899.

11. Sahu D, Kannan GM, Tailang M, Vijayaraghavan R. In vitro cytotoxicity of nanoparticles: a comparison between particle size and cell type. J Nanosci 2016. doi: 10.1155/2016/4023852.

12. Kim YS, Kim JS, Cho HS, Rha DS, Kim JM, Park JD, et al. Twenty-eight-day oral toxicity, genotoxicity, and gender-related tissue distribution of silver nanoparticles in Sprague-Dawley rats. Inhal Toxicol 2008;20(6):575-583.

13. Mohtashami M, Sepehriseresht S, Asli E, Boroumand MA, Ghasemi A. Synthesis of silver nanoparticles through chemical reduction and biosynthesis methods and evaluation of their antibacterial effects. RJMS 2013;19(103):65-74.

14. Burdus AC, Gherasim O, Grumezescu AM, Mogoanta L, Ficai $A$, Andronescu E. Biomedical applications of silver nanoparticles: an up-to-date overview. Nanomaterials 2018;8(9):681. doi: 10.3390/nano8090681

15. Peričin D, Krimer V, Trivić S, Radulović L. The distribution of phenolic acids in pumpkin's hull-less seed, skin, oil cake meal, dehulled kernel and hull. Food Chem 2009;113(2):450-456.

16. Sezik E, Yeşilada, E, Honda G, Takaishi Y, Takeda Y, Tanaka $\mathrm{T}$. Traditional medicine in Turkey $\mathrm{X}$. Folk medicine in Central Anatolia. J Ethnopharmacol 2001;75(2):95-115.

17. Kovács $D$, Igaz $N$, Keskeny $C$, Bélteky $P$, Tóth $T$, Gáspár R, et al. Silver nanoparticles defeat p53-positive and p53-negative osteosarcoma cells by triggering mitochondrial stress and apoptosis. Sci Rep 2016 Jun 13;6:27902.

18. Yang L, Kuang $\mathrm{H}$, Zhang $\mathrm{W}$, Aguilar $\mathrm{ZP}$, Wei $\mathrm{H}, \mathrm{Xu} \mathrm{H}$. Comparisons of the biodistribution and toxicological examinations after repeated intravenous administration of silver and gold nanoparticles in mice. Sci Rep 2017 Jun 12;7(1):3303.

19. van der Zande M, Vandebriel RJ, Van Doren E, Kramer E, Herrera Rivera Z, et al. Distribution, elimination, and toxicity of silver nanoparticles and silver ions in rats after 28-day oral exposure. ACS Nano 2012 Aug 9;6(8):7427-42.

20. Boroumand Z, Golmakani N, Boroumand S. Clinical trials on silver nanoparticles for wound healing. Nanomed J 2018;5(4):186-91. 
21. Seo SB, Dananjaya SH, Nikapitiya C, Park BK, Gooneratne R, Kim TY, Lee J, et al. Silver nanoparticles enhance wound healing in zebrafish (Danio rerio). Fish Shellfish 2017 Sep 1;68:536-45.

22. Gawish SM, El Din AAG, Ahmed HH, Farrag ARH, Abou-El Kheir A. Effect of newly synthesized polypropylene/silver nonwoven fabric dressing on incisional wound healing in rats. Maced $\mathrm{J}$ Med Sci 2014 Sep 15;7(3):395-403. doi: 10.3889/MJMS.18575773.2014.0407.

23. Agnihotri S, Mukherji S, Mukherji S. Size-controlled silver nanoparticles synthesized over the range 5-100nm using the same protocol and their antibacterial efficacy. RSC Adv 2014;4(8):3974-83.

24. Luca DC. Bone marrow: nonneoplastic normal neutrophil maturation [Internet]; 2012 [cited 2019 Jul 12]. Available from: http://www.pathologyoutlines.com/topic/ bonemarrowneutrophilmaturation.html.

25. Luca DC. Bone marrow: nonneoplastic normal mast cells [Internet]. 2012 [cited 2019 Jul 12]. Available from: http://www. pathologyoutlines.com/topic/bonemarrowmastcells.html.

26. Luca DC. Bone marrow: nonneoplastic normal eosinophils [Internet]; 2012 [cited 2019 Jul 11]. Available from: http://www. pathologyoutlines.com/topic/bonemarroweosinophils.html.

27. Shankar V. Soft tissue vascular: nonneoplastic normal vessels [Internet]; 2016 [cited 2019 Sep 10]. Available from: http://www. pathologyoutlines.com/topic/softtissuevascnormal.html.

28. Talas DU, Nayci A, Atis S, Polat A, Comelekoglu U, Bagdatoglu $C$, et al. The effects of corticosteroids on the healing of tracheal anastomoses in a rat model. Pharmacol Res 2002;45:299-304.

29. Gheibi N, Farzam A, Azhdari-Zarmehri H, Farsad F. The combined effect of caffeic acid and low-power laser on wound healing in male Wistar rats. J Babol Univ Med Sci 2015;17(1):63-9.

30. Kotwal GJ, Chien S. Macrophage differentiation in normal and accelerated wound healing results. Probl Cell Differ 2017;62:353364. doi: 10.1007/978-3-319-54090-0_14.

31. Andersson-Willman B, Gehrmann U, Cansu Z, BuerkiThurnherr T, Krug HF, Gabrielsson $S$ et al. Effects of subtoxic concentrations of $\mathrm{TiO} 2$ and $\mathrm{ZnO}$ nanoparticles on human lymphocytes, dendritic cells and exosome production. Toxicol Appl Pharmacol 2012;264:94-103.

32. Cortivo R, Vindigni V, lacobellis L, Abatangelo G, Pinton P, Zavan B. Nanoscale particle therapies for wounds and ulcers. Nanomed (Lond) 2010 Jun;5(4):641-56.

33. Eming SA, Martin P, Tomic-Canic M. Wound repair and regeneration: mechanisms, signaling, and translation. Sci Transl Med 2014 Dec 3;6(265):265sr6. doi: 10.1126/ scitranslmed.3009337

34. Ljubimov AV, Saghizadeh M. Progress in corneal wound healing. Prog Retin Eye Res 2015 Nov;49:17-45. doi: 10.1016/j. preteyeres.2015.07.002

35. Naghsh N, Aboutalebi F, Karam Seychani S. Designing a new nano-plant composite of Cucurbita pepo for wound repair of skin in male albino mice. JFUMS 2013;3(1):27-33.

36. Razavian MH, Safarpour E, Roshanai K, Yazdian MR, Heidarieh $\mathrm{N}$. Study of some biochemical and hematological parameters changes of Wistar rats blood parallel to oral nanosilver consumption. J Babol Univ Med Sci 2011;13(1):22-27.
37. Wijnhoven SWP, Peijnenburg WJGM, Herberts CA, Hagens WI, Oomen AG, Heugens EHW, et al. Nano-silver: a review of available data and knowledge gaps in human and environmental risk assessment. Nanotoxicol 2009;3(2):109-138.

38. Gheibi N, Edris M, Sofiabadi M, Samieirad F. Effect of silver nanoparticles orally consumption on blood biochemical factors in male rats. Res Med 2017;40(4):178-181. Available from: http:// pejouhesh.sbmu.ac.ir/article-1-1661-en.html

39. Yuan Y, Peng, Q, Gurunathan S. Silver nanoparticles enhance the apoptotic potential of gemcitabine in human ovarian cancer cells: combination therapy for effective cancer treatment. Int J Nanomedicine 2017;12:6487-6502. doi: 10.2147/IJN.S135482 